\title{
Clinicopathological correlation and post-resection outcomes of hepatic angiomyolipoma
}

\author{
Geunhyeok Yang ${ }^{1}$, Shin Hwang ${ }^{1}$, Chul-Soo Ahn ${ }^{1}$, Ki-Hun Kim ${ }^{1}$, Deok-Bog Moon ${ }^{1}$, \\ Tae-Yong $\mathrm{Ha}^{1}$, Gi-Won Song ${ }^{1}$, Dong-Hwan Jung ${ }^{1}$, Gil-Chun Park ${ }^{1}$, and Seung-Mo Hong ${ }^{2}$ \\ Departments of ${ }^{1}$ Surgery and ${ }^{2}$ Pathology, Asan Medical Center, \\ University of Ulsan College of Medicine, Seoul, Korea
}

\begin{abstract}
Backgrounds/Aims: Angiomyolipoma is a rare neoplasm of mesenchymal origin derived from perivascular epithelioid cells. Due to rarity, hepatic angiomyolipoma (HAML) has been often misdiagnosed as hepatocellular carcinoma (HCC) or other hypervascular liver tumors based on imaging studies. This study investigated the clinicopathological correlation and post-resection outcomes of HAML. Methods: This retrospective observational study included 40 patients who underwent hepatic resection (HR) for HAML between 2008 and 2018. Results: Mean age of the patients was $42.6 \pm 11.4$ years and there were $30(75.0 \%)$ females. Hepatitis B and C virus infection was present in 8 patients $(20.0 \%)$ and 1 patient $(2.5 \%)$, respectively. Preoperative diagnoses on imaging studies were HCC in $23(57.5 \%)$ patients, HAML in $14(35.0 \%)$ patients, focal nodular hyperplasia in $2(5.0 \%)$ patients, and hepatic adenoma in $1(2.5 \%)$ patient. Percutaneous liver biopsy was performed in $10(25.0 \%)$ patients and HAML was diagnosed in all patients. Only 3 patients $(7.5 \%)$ showed a slight elevation in the level of liver tumor markers. Major HR was performed in $10(25.0 \%)$. Laparoscopic HR was performed in $9(22.5 \%)$. The mean tumor size was $4.8 \pm 3.9 \mathrm{~cm}$ and single tumor was present in $38(95.0 \%)$ patients. Currently, all the patients are alive without tumor recurrence during the follow-up observation period of $75.7 \pm 37.3$ months. Conclusions: HAML is a rare form of primary liver tumor and is often misdiagnosed as HCC or other hypervascular tumors. Although HAML is benign in nature, it has malignant potential, thus resection is indicated if the tumor grows or malignancy cannot be excluded. (Ann Hepatobiliary Pancreat Surg 2021;25:215-220)
\end{abstract}

Key Words: Immunohistochemical stain; Perivascular epithelioid cell tumor; Mesenchymal origin; Malignant potential; Hepatocellular carcinoma

\section{INTRODUCTION}

Various types of primary tumors can develop in the liver, ranging from benign to malignant lesions with different cell origins. Hepatocellular carcinoma (HCC) and intrahepatic cholangiocarcinoma are the most common primary liver malignancies, but there is a wide range of rare liver tumors that require a differential diagnosis from these common hepatic malignancies.

In 2002, perivascular epithelioid cell tumors (PEComas) were classified as an independent entity according to the World Health Organization (WHO). ${ }^{1}$ The family of PEComas includes angiomyolipoma of the kidney and extra renal sites, clear cell sugar tumor of the lung and extra-pulmo- nary lymphangioleiomyomatosis, clear cell myomelanocytic tumor of the falciform ligament, and PEComa not otherwise specified. PEComas are very rarely diagnosed in anatomical locations other than the kidney and lung. ${ }^{2}$

Angiomyolipoma, which is a rare neoplasm of mesenchymal origin, is derived from perivascular epithelioid cells. This lesion is frequently detected in the kidney, with an incidence of $0.3 \%$ in the general population, and accounts for $3 \%$ of the renal masses. ${ }^{3}$ It is very rarely identified in the liver, thus there exists only a small number of available case series and reports in the literature. ${ }^{3-6} \mathrm{We}$ have previously reported a series of 23 cases of hepatic angiomyolipoma (HAML). ${ }^{6}$

Recently, there has been an increase in the diagnosis

Received: September 24, 2020; Revised: September 29, 2020; Accepted: October 1, 2020

Corresponding author: Shin Hwang

Department of Surgery, Asan Medical Center, University of Ulsan College of Medicine, 88 Olympic-ro 43-gil, Songpa-gu, Seoul 05505, Korea Tel: +82-2-3010-3930, Fax: +82-2-3010-6701, E-mail: shwang@amc.seoul.kr

Copyright (C) 2021 by The Korean Association of Hepato-Biliary-Pancreatic Surgery

This is an Open Access article distributed under the terms of the Creative Commons Attribution Non-Commercial License (http://creativecommons.org/ licenses/by-nc/4.0) which permits unrestricted non-commercial use, distribution, and reproduction in any medium, provided the original work is properly cited. Annals of Hepato-Biliary-Pancreatic Surgery • pISSN: 2508-5778 - eISSN: 2508-5859 
of HAML, primarily due to the frequent routine screening imaging studies for liver malignancy and the recent developments in imaging studies. ${ }^{7}$ However, it is still difficult to diagnose HAML through imaging studies, thus pathological confirmation is essential to diagnose HAML through immunohistochemical staining studies after percutaneous liver biopsy or hepatic resection (HR).

In the present study, we investigated the clinicopathological correlation and post-resection outcomes of 40 patients who underwent HR for HAML in our institution.

\section{MATERIALS AND METHODS}

\section{Patients}

The primary liver cancer database at our institution was extensively searched to identify patients diagnosed with HAML after HR. We identified 40 patients over a 11-year period from January 2008 to December 2018. During this study period, 12,854 cases of HR were performed for patients with various diseases in our institution; ${ }^{8}$ therefore, 40 cases of HAML comprised approximately $0.3 \%$ (40 of 12,854) of all HR cases.

The medical records of the patients were retrospectively reviewed following the approval of the Institutional Review Board at our institution (IRB No. 2019-1347), which waived the requirement for informed consent due to the retrospective nature of this study. This study was performed in accordance with the ethical guidelines of the World Medical Association Declaration of Helsinki 2013. The patients were followed up until August 2020 based on the medical record review and with the assistance of the National Health Insurance Service.

\section{Preoperative evaluation, surgical procedures, and postoperative follow-up}

Routine preoperative evaluation for primary liver tumors has been described elsewhere. ${ }^{9}$ In general, the HR patients with benign or borderline malignancy were followed up every 3-6 months during the first year after surgery and every 4-12 months thereafter. ${ }^{10-13}$

\section{Pathological diagnosis}

Formalin-fixed paraffin-embedded tissue samples were immunohistochemically stained with antibodies to human melanoma black-45 (HMB45), smooth muscle actin (SMA), and various other markers. The morphologic features and immunohistochemical profile for diagnosis of HAML are based on the 2010 WHO classification of the liver tumors. ${ }^{14}$

\section{Statistical analysis}

Numeric data are presented as means and standard deviation or as median and range. As there was no case of tumor recurrence, survival analysis was not performed. A $p$-value $<0.05$ was regarded as statistically significant. Statistical analyses were performed using SPSS version 22 (IBM, New York, NY).

\section{RESULTS}

\section{Patient demographics and preoperative diagnosis}

The mean age of the patients was $42.6 \pm 11.4$ years. There were $30(75.0 \%)$ female patients and $10(25.0 \%)$ male patients. Hepatitis B virus (HBV) infection was present in $8(20.0 \%)$ patients, and one (2.5\%) patient had hepatitis $\mathrm{C}$ virus infection.

The initial clinical manifestations were abdominal pain or discomfort $(n=9)$, fatigue $(n=2)$, and fever $(n=1)$. The other 28 patients $(70.0 \%)$ had no specific symptoms and the liver mass was detected incidentally on routine health screening. One patient had undergone kidney transplantation 17 years before.

The preoperative diagnoses on imaging studies were HAML in 14 (35.0\%) patients (Fig. 1), HCC in 23 (57.5\%) patients (Fig. 2), focal nodular hyperplasia in $2(5.0 \%)$ patients, and hepatic adenoma in $1(2.5 \%)$ patient. Two patients had undergone transcatheter arterial chemoembolization under the clinical diagnosis of HCC.

Percutaneous liver biopsy was performed in 10 patients with an initial diagnosis of HAML $(n=4), \operatorname{HCC}(n=3)$, fibrous nodular hyperplasia $(\mathrm{n}=2)$, and hepatic adenoma $(n=1)$ and HAML was pathologically diagnosed in all patients who had undergone liver biopsy. Five patients were observed for 1 to 7 years after liver biopsy, and finally they underwent HR due to progressive tumor growth. The final preoperative diagnoses for HR were HAML in 20 $(50.0 \%)$ patients and $\mathrm{HCC}$ in $20(50.0 \%)$ patients.

The mean and median levels of preoperative alpha-fetoprotein (AFP; reference: $7.5 \mathrm{ng} / \mathrm{ml}$ ) were $4.0 \pm 10.9 \mathrm{ng} / \mathrm{ml}$ and $2.1 \mathrm{ng} / \mathrm{ml}$, those of protein induced by Vitamin $\mathrm{K}$ ab- 

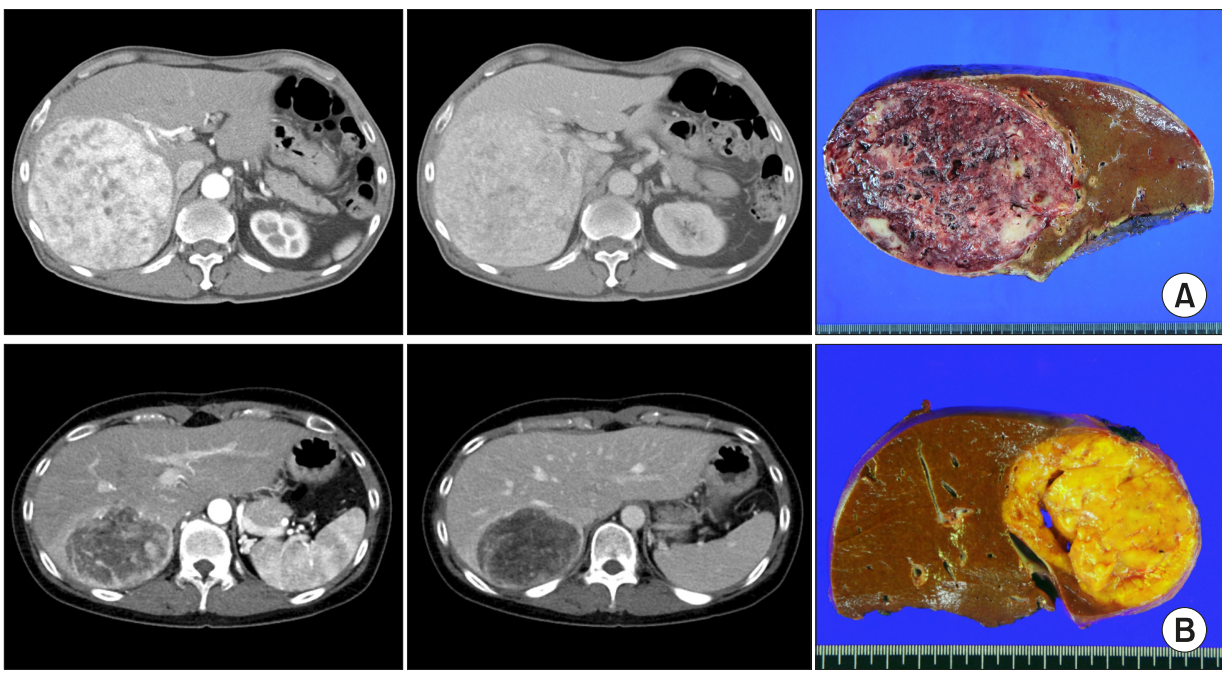

Fig. 1. Preoperative computed tomography findings and gross photographs of the surgical specimens of patients with a clinical diagnosis of hepatic angiomyolipoma. (A) A $17 \mathrm{~cm}$-sized large mass was presented with abdominal discomfort as a result of compression symptoms. (B) A $8.4 \mathrm{~cm}$-sized mass was detected at routine follow-up imaging studies following kidney transplantation. (C) A $2.7 \mathrm{~cm}$-sized mass was detected at the routine health screening.
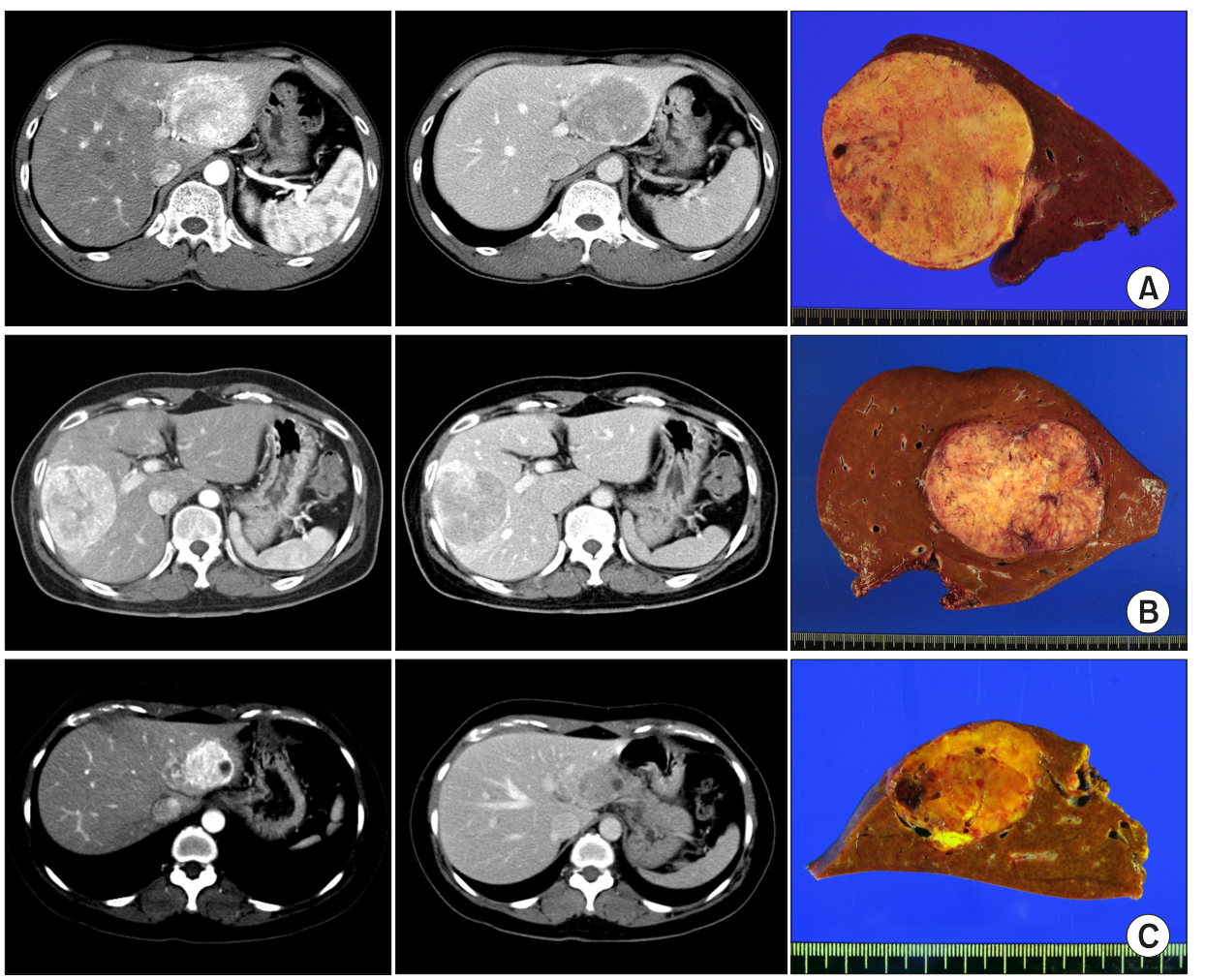

Fig. 2. Preoperative computed tomography findings and gross photographs of the surgical specimens of patients with a clinical diagnosis of hepatocellular carcinoma. (A) A $8 \mathrm{~cm}$-sized mass was detected at the routine health screening. (B) A 8 $\mathrm{cm}$-sized mass was presented with abdominal discomfort. (C) A $4 \mathrm{~cm}$-sized mass was detected at the routine health screening.

sence or antagonist-II (PIVKA-II; reference: $40 \mathrm{mAU} / \mathrm{ml}$ ) were $20.1 \pm 7.5 \mathrm{mAU} / \mathrm{ml}$ and $18 \mathrm{mAU} / \mathrm{ml}$, and those of carbohydrate antigen 19-9 (CA19-9; reference: $37 \mathrm{ng} / \mathrm{ml}$ ) were $12.3 \pm 16.2 \mathrm{ng} / \mathrm{ml}$ and $8.1 \mathrm{ng} / \mathrm{ml}$, respectively. Two patients showed slightly elevated AFP levels $(64.9 \mathrm{ng} / \mathrm{ml}$ and $8.6 \mathrm{ng} / \mathrm{ml}$, respectively) and one patient showed con- 
currently elevated PIVKA-II (48 mAU/ml) and CA19-9 (94.5 ng/ml) levels. The remaining 37 patients $(92.5 \%)$ showed no elevation in preoperative AFP, PIVKA-II and CA19-9 levels.

\section{Outcomes after hepatic resection}

The indocyanine green retention test at 15 minutes yielded a mean value of $10.1 \pm 4.1 \%$. Four patients $(10.0 \%)$ underwent preoperative portal vein embolization for right hepatectomy. The extent of hepatic resection comprised of right hepatectomy $(n=6[25.0 \%])$, left hepatectomy $(n=2$ $[5.0 \%])$, central bisectionectomy $(\mathrm{n}=2[5.0 \%])$, right anterior sectionectomy $(\mathrm{n}=2[5.0 \%])$, right posterior sectionectomy $(\mathrm{n}=2[5.0 \%])$, left lateral sectionectomy $(\mathrm{n}=3[7.5 \%])$, left medial sectionectomy $(\mathrm{n}=1[2.5 \%])$, and segmentectomy/partial hepatectomy $(\mathrm{n}=18[45.0 \%])$. Laparoscopic HR was performed in 9 patients (22.5\%). All operations were regarded as macroscopic curative resection with tumor-negative resection margins. None of our patients experienced major surgical complications that required any intervention or re-exploration.

The mean and median tumor sizes were $4.8 \pm 3.9 \mathrm{~cm}$ and $3.5 \mathrm{~cm}$, respectively. Only $2(5.0 \%)$ patients had two tumors and the other $38(95.0 \%)$ patients had a single tumor. The location of the tumor was the right liver in 30 $(75.0 \%)$ patients and the left liver in $10(25.0 \%)$ patients. Immunohistochemical staining exhibited positive findings for HMB45 in all 40 patients and SMA in all of 30 patients.

Currently, during the follow-up observation period of 75.7 \pm 37.3 months (range, 21-149 months), all the patients are alive without recurrence of HAML.

\section{DISCUSSION}

HAML is a rare liver tumor of mesenchymal origin. In the present study, the majority of patients were diagnosed with or suspected of HCC based on the imaging studies owing to hypervascularity of the tumor and half of patients underwent HR under the final preoperative diagnoses of HCC. HAML is usually asymptomatic unless nonspecific abdominal pain or discomfort develops due to the growth of tumor. As a result, the majority of HAML lesions have been incidentally identified in liver imaging studies during health screening tests.
The features of HAML in imaging studies are associated with the histological components of the tumor. Most of the tumors were devoid of adipose tissue, thus fat attenuation was rarely observed in computed tomography and magnetic resonance imaging studies. ${ }^{15,16}$ Meanwhile, nearly all the tumors are markedly enhanced in the arterial phase, thus they are visualized as hypervascular tumors. ${ }^{17}$ There are two types of enhancement patterns in the portal venous/delayed phase: lesions with abundant central vessels exhibiting a rapid contrast decrease or lesions with small or no vessels demonstrating prolonged enhancement. $^{17,18}$ In addition, most of the tumors exhibited significantly reduced contrast enhancement in the portal venous and delayed phases. ${ }^{15}$

So far, there is no specific imaging technique or imaging finding that can discern HAML from other liver tumors. Consequently, the majority of HAML has been diagnosed with HCC or other hypervascular tumors until pathological diagnosis with percutaneous liver biopsy or HR. ${ }^{4,15}$ In the present study, all 9 patients with HBV or hepatitis $\mathrm{C}$ virus infection were preoperatively diagnosed with HCC and none of them underwent preoperative liver biopsy.

HAML is finally diagnosed only after the outcomes of the pathological studies. Histologically, these tumors comprise of aggregates and sheets of mature adipose tissue, tortuous thick-walled vessels, and perivascular muscle cell proliferation. The epithelioid concept is applicable when 1 of the 3 components of these tumors, particularly the smooth muscle cells, has a rounded or polygonal appearance, with a large round nucleus, prominent nucleoli, and abundant eosinophilic cytoplasm. Such perivascular epithelioid cells are one of the diagnostic clues. ${ }^{3}$

In the present study, percutaneous liver biopsy was performed in 10 patients under the clinical diagnosis of HAML, HCC, fibrous nodular hyperplasia or hepatic adenoma, and HAML was pathologically diagnosed in all patients who had undergone liver biopsy. Although percutaneous liver biopsy led to the correct diagnosis of hepatic AML in the present study, previously it has been reported that correct diagnosis of this condition through needle biopsy is difficult due to the heterogeneous appearance of HAML. ${ }^{19}$

HAML is a benign disease. Nevertheless, it is difficult to discern HAML from various malignant hepatic lesions. 
Thus, hepatic tumors mimicking HCC or other hypervascular tumors as well as tumors showing progressive growth are reasonably indicated for surgical treatment. Surgical resection is the only potentially curative treatment for primary PEComas. ${ }^{20}$ In practice, surgical resection is the only accepted treatment for patients with large or multiple tumors with malignant potential. ${ }^{21,22} \mathrm{~A}$ case of liver transplantation due to tumor recurrence following HR has previously been reported in the literature. ${ }^{23}$

On the contrary, an asymptomatic small tumor diagnosed with HAML through percutaneous needle biopsy is usually not indicated for surgical resection. However, HAML should be regularly followed up lifelong as this tumor can grow and induce compressive symptoms, tumor rupture and malignant transformation..$^{20,24,25}$ Conservative treatment has been recommended for patients with tumors smaller than $5 \mathrm{~cm}$; HAML diagnosed by percutaneous needle biopsy; good compliance for long-term follow-up study. $^{26}$

The present study had limitations of note. This is a retrospective, single-center observation study with a relatively small number of patients. Thus, multi-center studies are necessary to collect more cases. The follow-up observation period was not sufficiently long to evaluate the lifelong risk of tumor recurrence or malignant transformation.

In conclusion, HAML is reported as a rare primary liver tumor. It is often misdiagnosed as HCC or other hypervascular hepatic tumors. This disease is benign in nature, but the definite diagnosis is not possible with current imaging studies and there exists a risk of malignant transformation during long-term follow-up. Therefore, close observation is recommended for most of the biopsy-proven small HAMLs, but surgical treatment is indicated under conditions of progressive growth of the tumor or exclusion of hepatic malignancy.

\section{CONFLICT OF INTEREST}

None of the authors have any conflicts of interest.

\section{ORCID}

Geunhyeok Yang: https://orcid.org/0000-0002-8260-1525

Shin Hwang: https://orcid.org/0000-0002-9045-2531
Chul-Soo Ahn: https://orcid.org/0000-0002-3844-3646

Ki-Hun Kim: https://orcid.org/0000-0002-4016-0995

Deok-Bog Moon: https://orcid.org/0000-0002-8209-3540

Tae-Yong Ha: https://orcid.org/0000-0001-9932-0212

Gi-Won Song: https://orcid.org/0000-0002-4235-0434

Dong-Hwan Jung: https://orcid.org/0000-0001-5984-023X

Gil-Chun Park: https://orcid.org/0000-0003-1631-3258

Seung-Mo Hong: https://orcid.org/0000-0002-8888-6007

\section{AUTHOR CONTRIBUTIONS}

Conceptualization: SH. Data curation: GY, CSA, KHK, DBM. Formal analysis: GY, SH. Methodology: GWS, DHJ, GCP, SMH. Project administration: SH. Visualization: SH. Writing - original draft: GY SH. Writing - review \& editing: All.

\section{REFERENCES}

1. Martignoni G, Pea M, Reghellin D, Zamboni G, Bonetti F. PEComas: the past, the present and the future. Virchows Arch 2008;452:119-132.

2. Ameurtesse H, Chbani L, Bennani A, Toughrai I, Beggui N, Kamaoui I, et al. Primary perivascular epithelioid cell tumor of the liver: new case report and literature review. Diagn Pathol 2014;9:149.

3. Ortiz S, Tortosa F. Epithelioid angiomyolipoma of the liver: clinicopathological correlation in a series of 4 cases. Rev Esp Enferm Dig 2016;108:27-30.

4. Chang Z, Zhang JM, Ying JQ, Ge YP. Characteristics and treatment strategy of hepatic angiomyolipoma: a series of 94 patients collected from four institutions. J Gastrointestin Liver Dis 2011;20:65-69.

5. Shi H, Cao D, Wei L, Sun L, Guo A. Inflammatory angiomyolipomas of the liver: a clinicopathologic and immunohistochemical analysis of 5 cases. Ann Diagn Pathol 2010;14:240-246.

6. Jung DH, Hwang S, Hong SM, Kim KH, Ahn CS, Moon DB, et al. Clinico-pathological correlation of hepatic angiomyolipoma: a series of 23 resection cases. ANZ J Surg 2018;88:E60-E65.

7. Lencioni R. Surveillance and early diagnosis of hepatocellular carcinoma. Dig Liver Dis 2010;42 Suppl 3:S223-S227.

8. Cho HD, Hwang S, Lee YJ, Park KM, Kim KH, Kim JC, et al. Changes in the types of liver diseases requiring hepatic resection: a single-institution experience of 9016 cases over a 10-year period. Korean J Hepatobiliary Pancreat Surg 2016;20: 49-52.

9. Hwang S, Ha TY, Song GW, Jung DH, Ahn CS, Moon DB, et al. Quantified risk assessment for major hepatectomy via the indocyanine green clearance rate and liver volumetry combined with standard liver volume. J Gastrointest Surg 2015;19:1305-1314.

10. Lee SG, Hwang S. How I do it: assessment of hepatic functional reserve for indication of hepatic resection. J Hepatobiliary Pancreat Surg 2005;12:38-43.

11. Hwang S, Lee YJ, Kim KH, Ahn CS, Moon DB, Ha TY, et al. The impact of tumor size on long-term survival outcomes after resection of solitary hepatocellular carcinoma: single-in- 
stitution experience with 2558 patients. J Gastrointest Surg 2015; 19:1281-1290

12. Hwang S, Lee YJ, Song GW, Park KM, Kim KH, Ahn CS, et al. Prognostic impact of tumor growth type on 7th AJCC staging system for intrahepatic cholangiocarcinoma: a single-center experience of 659 cases. J Gastrointest Surg 2015;19:1291-1304.

13. Yoon YI, Hwang S, Lee YJ, Kim KH, Ahn CS, Moon DB, et al. Postresection outcomes of combined hepatocellular carcinoma-cholangiocarcinoma, hepatocellular carcinoma and intrahepatic cholangiocarcinoma. J Gastrointest Surg 2016;20:411-420.

14. Miettinen M, Fletcher CD, Kindblom LG, Zimmermann A, Tsui WMS. Mesenchymal tumours of the liver. In: Bosman FT, Carneiro F, Hruban RH, Theise ND, ed. WHO classification of tumours of the digestive system. 4th ed. Lyon: International Agency for Research on Cancer, 2010:241-250.

15. Ji JS, Lu CY, Wang ZF, Xu M, Song JJ. Epithelioid angiomyolipoma of the liver: $\mathrm{CT}$ and MRI features. Abdom Imaging 2013;38:309-314.

16. Tryggvason G, Blöndal S, Goldin RD, Albrechtsen J, Björnsson J, Jónasson JG. Epithelioid angiomyolipoma of the liver: case report and review of the literature. APMIS 2004;112:612-616.

17. Xu PJ, Shan Y, Yan FH, Ji Y, Ding Y, Zhou ML. Epithelioid angiomyolipoma of the liver: cross-sectional imaging findings of 10 immunohistochemically-verified cases. World J Gastroenterol 2009; 15:4576-4581.

18. Xiao W, Zhou M, Lou H, Wang Z, Zhang M. Hemodynamic characterization of hepatic angiomyolipoma with least amount of fat evaluated by contrast-enhanced magnetic resonance angiography. Abdom Imaging 2010;35:203-207.

19. Agaimy A, Vassos N, Croner RS, Strobel D, Lell M. Hepatic angiomyolipoma: a series of six cases with emphasis on pathological-radiological correlations and unusual variants diagnosed by core needle biopsy. Int J Clin Exp Pathol 2012;5:512-521.

20. Bleeker JS, Quevedo JF, Folpe AL. "Malignant" perivascular epithelioid cell neoplasm: risk stratification and treatment strategies. Sarcoma 2012;2012:541626.

21. Mizuguchi T, Katsuramaki T, Nobuoka T, Nishikage A, Oshima $\mathrm{H}$, Kawasaki $\mathrm{H}$, et al. Growth of hepatic angiomyolipoma indicating malignant potential. J Gastroenterol Hepatol 2004;19: 1328-1330.

22. Deng YF, Lin Q, Zhang SH, Ling YM, He JK, Chen XF. Malignant angiomyolipoma in the liver: a case report with pathological and molecular analysis. Pathol Res Pract 2008;204:911918.

23. Wang WT, Li ZQ, Zhang GH, Guo Y, Teng MJ. Liver transplantation for recurrent posthepatectomy malignant hepatic angiomyolipoma: a case report. World J Gastroenterol 2015;21: 3755-3758.

24. Fukuda Y, Omiya H, Takami K, Mori K, Kodama Y, Mano M, et al. Malignant hepatic epithelioid angiomyolipoma with recurrence in the lung 7 years after hepatectomy: a case report and literature review. Surg Case Rep 2016;2:31.

25. Occhionorelli S, Dellachiesa L, Stano R, Cappellari L, Tartarini D, Severi S, et al. Spontaneous rupture of a hepatic epithelioid angiomyolipoma: damage control surgery. A case report. G Chir 2013;34:320-322.

26. Brimo F, Robinson B, Guo C, Zhou M, Latour M, Epstein JI. Renal epithelioid angiomyolipoma with atypia: a series of 40 cases with emphasis on clinicopathologic prognostic indicators of malignancy. Am J Surg Pathol 2010;34:715-722. 